\title{
No Correlation between Fagerstrom Test for Nicotine Dependence Scores to Lipopolysaccharide Marker in Thai Smokers
}

\author{
Parama Pratummas a,c , Phakkharawat Sittiprapaporn a, ${ }^{\text {a }}$, Chaiyavat Chaiyasut ${ }^{\mathrm{b}}$, Sasithorn Sirilun ${ }^{\mathrm{b}}$, \\ Thamthiwat Nararatwanchai ${ }^{\mathrm{c}}$ \\ ${ }^{a}$ Neuropsychological Research Laboratory, Department of Anti-Aging and Regenerative Science, School of Anti-Aging and Regenerative \\ Medicine, Mae Fah Luang University, Bangkok 10110, Thailand \\ ${ }^{b}$ Innovation Centre for Holistic Health, Nutraceuticals and Cosmeceuticals, Faculty of Pharmacy, Chiang Mai University, Chiang Mai, \\ 50200, Thailand \\ ${ }^{c}$ Department of Anti-Aging and Regenerative Medicine, School of Anti-Aging and Regenerative Medicine, Mae Fah Luang University, \\ Bangkok 10110, Thailand \\ Corresponding author: *wichian.sit@mfu.ac.th
}

\begin{abstract}
Cigarette smoking is a combination of thousands of synthetic compounds that contribute straightforwardly or by implication to the addiction of cigarette smoking with inflammation, although a lot more may exist. Genome-wide association studies (GWAS) have unequivocally shown that variety in neuronal nicotinic acetylcholine receptor subunit $\alpha 5$ (CHRNA5) and in cytochrome P450 $2 A 6$ (CYP2A6) anticipated smoking substantialness, later period of smoking discontinuance. The relationship between the Fagerstrom Test for Nicotine Dependence and the Lipopolysaccharide marker in Thai smokers was proposed in this study. We investigated fourteen Thai smokers in Mahasarakham province who scored 4 or higher on the Fagerstrom Test for Nicotine Dependence. We provided them surveys about their personal information, administered the Fagerstrom Test for Nicotine Dependence, and continued the Lipopolysaccharide marker blood tests. The value of $R$ in Pearson connection was 0.4438 . Although it found a positive correlation, the relationship between Fagerstrom Test for Nicotine Dependence and Lipopolysaccharide level was weak due to no correlation. In addition, the value of $\mathrm{R} 2$, the coefficient of determination, was $0.197(p=0.1119)$. Further studies are needed to investigate more the relationship between smoking and inflammation.
\end{abstract}

Keywords - Smokers; cigarette smoking; nicotine dependence; lipopolysaccharide; inflammation.

Manuscript received 25 Nov. 2020; revised 9 Aug. 2021; accepted 9 Sep. 2021. Date of publication 31 Oct. 2021. IJASEIT is licensed under a Creative Commons Attribution-Share Alike 4.0 International License.

\section{INTRODUCTION}

Bioinformatics began more than fifty years ago when personal computers were still a hypothesis, and DNA could not yet be sequenced. During the 1960 s, the primary again peptide sequence constructing agent, the principal protein succession information base, and the main amino acid replacement model for phylogenetics were created. Through the 1970s and the 1980s, equal advances in atomic science and software engineering set the way for progressively complex undertakings, for example, examining total genomes. In the 1990-the 2000s, utilization of the web, combined with cutting-edge sequencing, prompted an outstanding flood of information and a quick multiplication of bioinformatics instruments. Today, bioinformatics faces different missions, for example, dealing with Huge
Information, guaranteeing the reproducibility of results, and appropriate coordination into scholarly educational plans [1].

Tobacco smoking is a mixture of hundreds of synthetic chemicals created by chewing or warming Tobacco. The enormous variety of mixtures found in cigarette smoking may be divided into general groups regarding realized objective effects. Cigarette smoking is now recognized to include many cancer-causing toxins. Although nicotine is the most addictive cigarette smoking element, several synthetic chemicals also contribute to the addictive concept of cigarette smoking, either directly or indirectly. Nicotine, carbon monoxide, receptive oxidant substances (ROS), and acrolein are among the more significant tobacco smoke poisons with immunomodulatory potential, albeit a lot more may exist [1], [2]. Nicotine, an essential part of Tobacco, produces wanting and withdrawal impact both in people and creatures. Nicotine has atomic, neuroanatomical, and pharmacological 
similarities to other addictive drugs, particularly those that improve psychological capacity. Nicotine's function is primarily seen in the brain via nicotinic acetylcholine receptors. It stimulates Ach delivery and digestion by energizing presynaptic acetylcholine receptors. It also energizes the dopaminergic system, resulting in increased dopamine convergence in the nucleus accumbent. As per different specialists, this property of nicotine is liable for strengthening conduct change and reliance on nicotine. Different analysts have also portrayed that some nondopaminergic frameworks are likewise included for the remunerating impact of nicotinic withdrawal [2].

In European Americans, a large-scale genome-wide association study (GWAS) identified 18 sites associated with persistent and never-smokers, one site associated with African Americans, and one site associated with Hispanic Americans. Focusing on the actual interpretation of dozens of qualities is the key loci co-limited with quantitative expression characteristics or chromatin interaction loci. Smoking instructions inherited 209 varieties of characteristics, 33 of which are that smoking is the main or important factor.

This extensive GWAS of the vertical smoking phenotype in different populations contributes to our understanding of the genetic susceptibility of smoking behavior [3]. The two genomic targets in GWAS are related to smoking weight, lung cancer, and chronic obstructive pulmonary disease, although their organic credibility is shown. GWAS clearly shows that the diversity of the $\alpha 5$ subunit of the neuronal nicotinic acetylcholine receptor (CHRNA5), which encodes the quality of the $\alpha 5$ nicotinic acetylcholine receptor (AChR) subunit, can predict the weight of smoking, the late time to stop smoking, smoking, COPD (chronic obstructive pulmonary disease) and lung cancer and early death. Similarly, the diversity of cytochrome P450 2A6 (CYP2A6) (which encodes the basic chemical's quality) also heralds more severe cigarette use and explosive smoking suspensions and smoking-related illnesses as hypertension and lung cancer. These advances in our understanding of genomic biomarkers associated with smoking-related blunting and mortality have established a framework for using genomes to reduce smoking [4].

The Fagerstrom Test for Nicotine Dependence (FTND) is the most generally utilized apparatus for estimating nicotine reliance. It is a non-obtrusive and simple to-acquire selfreport device that conceptualizes reliance through physiological and conducts side effects [5]. The FTND includes questions concerning the number of cigarettes smoked per day, the time of the first cigarette, the difficulty of quitting smoking while ill or contraindicated, the type of cigarette a person would prefer not to smoke, and the recurrence of smoking throughout the day. While the FTND has numerous qualities, which are brief, simple to direct, and generally utilized. It has been censured as being all the more a proportion of actual resistance than a proportion of the characteristics, for example, psychosocial, that may add to nicotine reliance. Extra inquiries have been built up that cover different parts of smoking conduct, for example, drive (wanting and withdrawal/impulse), congruity (routineness of smoking), decrease and discontinuance endeavors (want to chop down or stop), automaticity, and smoking mindfulness, which different specialists have distinguished as describing tobacco dependence [5], [6].
In contrast with different phases of smoking, known loci for nicotine dependence are restricted. CHRNB3-CHRNA6 (chr8p11), DBH (chr9q34), CHRNA5-CHRNA3-CHRNB4 (chr15q25), DNMT3B and NOL4L (chr20q11), and CHRNA4 (chr20q13) are the only six reproducible genomewide crucial loci that have been identified. Complete comprehension of the hereditary qualities of fundamental nicotine dependence is required, as it could assist with anticipating the probability of stopping smoking, withdrawal seriousness, reaction to treatment, and wellbeing-related results [6].

Smoking affects various degrees of inflammation. It focuses on genetic data (DNA and RNA), adjusts the structure and capabilities of proteins, modifies pathways and circulation, and improves the effects at the cell and organ levels. The effects of smoking are caused by a range of substances found in the gaseous and tar phases of the product. There are few direct repercussions, such as oxidative damage to lipids, proteins, and DNA, the release of nicotinic acetylcholine receptors, and potentially the formation of transient receptor channels in the intestinal epithelium or neurons. Significant changes in the microbiome's structure and epigenetic modification of protection cells and intestinal epithelial cells are the indirect impacts. It is unclear if cigarette smoke can generate major epigenetic changes in commensal microbes in the intestine. Since gut microbes and their objects have a stable connection to host tissues and can change their capabilities, more research is needed in this area. Epigenetic changes can clarify the phenotypic contrast within inflammation. Advances in sequencing methods and their examinations help identify specific epigenetic changes in cells and what these changes mean for cellular capabilities and cooperation within tissues and with other organs or life forms [7].

Smoking is believed to affect several natural mediators of inflammation by affecting insensitive burning cells, leading to a state of immunosuppression. The latest evidence suggests that the atomic components behind the regulation of inflammation caused by smoking mainly include the NF-kB family by initiating a subordinate and autonomous IKK pathway. Although NF-kB was released, several transcription factors were also involved, including GATA, PAX5, and Smad 3/4 [6], [7]. Inflammation can occur in unanticipated ways, and LPS is a key component in this process. This recognition, also known as endotoxin, is found throughout the world and is the most well-known molecular form linked with bacteria. The human immune system uses TLR-4 to recognize extracellular lipopolysaccharide, a component of Gramnegative bacteria. It shows that the toll-like receptor 4 is membrane-bound and can detect lipopolysaccharides in the extracellular or endosome environment. Regardless of whether the additional sensors play a role in recognizing lipopolysaccharides in the cytoplasm, it is not clear so far.

The last decade has witnessed the abnormal development of Toll-like receptor 4-independent lipopolysaccharide detection pathways. First, TRP channel has been classified as a non-Toll-like receptor membrane-bound sensor for lipopolysaccharide, and second, aspase-4/5 (and caspase-11 in mice) has been developed as a lipopolysaccharide sensor cytoplasmic sensor. These confirmation frames do not have excess capacity and allow the host to rapidly perceive, react, 
and kill lipopolysaccharide-bearing microorganisms in various ways and freely, which is how the host often comes into contact with lipopolysaccharide.

Alternatively, overactivation of these pathways, similar to sepsis, usually leads to multiple organ disappointment and host disappearance without the need for clinical adjustment. There are countless different ways to perceive lipopolysaccharides, underscoring the importance of this particle as a molecular model associated with microorganisms [8]. Lipopolysaccharide is a protein found in gram-negative bacteria' outer layer. Although it is known to operate on a variety of receptors, its primary target is the toll-like receptor 4. Lipopolysaccharide initiation of the toll-like receptor 4 requires a variety of downstream linkers, such as MyD88, TRIF, TRAM. This is the basis for tagging receptors. The registration of these linkers can develop even more downward pathways, which are completed during the initiation of the registration factors, which are essentially prompting a large number of pro-inflammatory genes. [9], [10]. Accordingly, this examination is expected to propose a connection between nicotine reliance appeared by FTND and inflammation state exhibited by lipopolysaccharide in Thai smokers in the bioinformatics way.

\section{MATERIALS AND METHOD}

The association between the FTND and the Lipopolysaccharide marker in Thai smokers was investigated in this study. The investigation was certified by and performed under Mae Fah Luang University's Research Ethics Committee in Thailand.

\section{A. Participants}

Adult smokers between the ages of 18 and 70 who live in Thailand are the subjects of this study. Our sample is 18-70year-old male or female smokers living in Mahasarakham province, Thailand. They have established rules for inclusion. All of them are within the range of 1 and 5 years of smoking. Fagerstrom nicotine dependence test scores $\geq 4$, no pregnancy and breastfeeding. We analyzed fourteen themes in one meeting.

\section{B. Intervention}

Initially, we appointed participants to make a plan in the initial segment of the day. At the plan, we explained the objectives, procedure, points of interest, and assessment responses in nuances. After that, participants intentionally checked the informed consent concerning the investigation. We provide them with questions about the individual information, FTND. Six questions are included in the FTND. The scores are as follows: (1) How long did you smoke your first cigarette after waking up? [Within the initial five minutes (3 scores), six to thirty minutes ( 2 scores), thirty-one to sixty minutes (one score), after sixty minutes (zero score)]; (2) Do you find it difficult to quit smoking in a place where smoking is prohibited? [Yes (one score), no (zero score)]; (3) What smoking do you most want to quit? [The first morning (one score), the other (zero score)]; (4) How many cigarettes a day do you smoke? [Below ten (zero score), ten to twenty (one score), twenty-one to thirty (two scores), thirty-one to three or more (three scores)]; (5) Do you smoke more frequently in the morning? [Yes (one score), no (zero score)]; (6) Do you smoke even if you are sick in bed most of the day? [Yes (one score), no (zero score)]. These appear in Table 1. In this sense, when each of the six reactions is added, the Fagerstrom test score for nicotine dependence ranges from 0 to 10 . The greater the score, the stronger the addiction [11].

TABLE I

FAGERSTROM TEST FOR NiCOTINE DEPENDENCE

\begin{tabular}{|c|c|c|}
\hline Questions & Answers & Points \\
\hline \multirow{4}{*}{$\begin{array}{l}\text { How soon after waking do you } \\
\text { smoke your first cigarette? }\end{array}$} & $\begin{array}{l}\text { Within the initial } \\
\text { five minutes }\end{array}$ & 3 \\
\hline & 6 to 30 minutes & 2 \\
\hline & 31 to 60 minutes & 1 \\
\hline & After 60 minutes & 0 \\
\hline \multirow{2}{*}{$\begin{array}{l}\text { Do you find it difficult to } \\
\text { refrain from smoking in places } \\
\text { where it is forbidden? }\end{array}$} & Yes & 1 \\
\hline & No & 0 \\
\hline \multirow{2}{*}{$\begin{array}{l}\text { What smoking do you most } \\
\text { want to quit? }\end{array}$} & $\begin{array}{l}\text { The first in the } \\
\text { morning }\end{array}$ & 1 \\
\hline & Another & 0 \\
\hline \multirow{4}{*}{$\begin{array}{l}\text { How many cigarettes a day do } \\
\text { you smoke? }\end{array}$} & 10 or fewer & 0 \\
\hline & 10 to 20 & 1 \\
\hline & 21 to 30 & 2 \\
\hline & 31 or more & 3 \\
\hline \multirow{4}{*}{$\begin{array}{l}\text { Do you smoke more frequently } \\
\text { in the morning? } \\
\text { Do you smoke even if you are } \\
\text { sick in bed most of the day? }\end{array}$} & Yes & 1 \\
\hline & No & 0 \\
\hline & Yes & 1 \\
\hline & No & 0 \\
\hline
\end{tabular}

Therefore, we perform a lipopolysaccharide blood test to record the level of inflammation, collect plasma using EDTA as an anticoagulant, centrifuge at $1000 \mathrm{xg}$ for 15 minutes, sort at 2 to 8 degrees Celsius in 30 minutes, and store samples at minus 20 degrees Celsius or minus 80 degrees Celsius, avoid the freeze-thaw cycle of remixing and centrifuge the sample again after thawing before testing. This lipopolysaccharide measurement uses MyBioSource's sandwich catalyst quantitative immunoassay program. The dominant lipopolysaccharide neutralizer has been pre-coated on the microtiter plate. The principles and tests are sucked into the hole, and the fixed immune response limits any lipopolysaccharide present. After removing any unbound material, an immunizing agent that biotin formation for lipopolysaccharides is carefully targeted in the wells. After washing, the wells were treated with horseradish peroxidase (HRP) and avidin.

After washing, the substrate array is introduced to the well to eliminate any unbound avidin protein reagent, and a shadow is created relative to the bound lipopolysaccharide measurement in the bottom layer. Stop the advancement of the shadow and estimate the intensity of the shadow. Position change $6.25 \mathrm{pg} / \mathrm{ml}-400 \mathrm{pg} / \mathrm{ml}$. The recognizable base portion of human lipopolysaccharide is usually less than $1.56 \mathrm{pg} / \mathrm{ml}$. The sensitivity or lower limit of detection (LLD) of this test is characterized as the minimum protein binding that can be separated from zero. The estimate of the D.O. average of the 20 replicates that met the zero standard plus its three standard deviations. This method has a high sensitivity and specificity for the recognition of human lipopolysaccharides. No attention was paid to the critical cross-reactivity or impedance between human lipopolysaccharides and analogs. 


\section{Data analysis}

The Use descriptive analysis, mean, standard deviation, and Pearson correlation to evaluate and analyze all results to measure the strength of their association. A $p$-value of less than 0.05 was regarded as statistically significant.

\section{RESULTS AND DISCUSSION}

\section{A. Demographic information of the participants}

TABLE II

DEMOGRAPHIC DATA

\begin{tabular}{lcc}
\hline \multicolumn{1}{c}{ Characteristics } & $\begin{array}{c}\text { Number } \\
\text { (Percentage) }\end{array}$ & Mean \pm SD \\
\hline Gender & $13(92.9)$ & - \\
Male & $1(7.1)$ & - \\
Female & $1(7.1)$ & \\
Age & $5(35.7)$ & $40.57 \pm 13.32$ \\
Under 20 & $6(42.9)$ & \\
$20-39$ & $2(14.3)$ & \\
$40-59$ & $7(50.0)$ & - \\
60 and above & $7(50.0)$ & - \\
Status & & \\
Single & & \\
Married &
\end{tabular}

Based on Table 2 of demographic information, all participants were 13 men and 1 woman, representing $92.9 \%$ and $7.1 \%$ of all participants, respectively. There is only one mature under 20 years of age, which represents about $7.1 \%$. Five persons aged 20 to 39 years and six persons aged 40 to 59 years accounted for $35.7 \%$ and $42.9 \%$ of all participants, respectively. The proportion of the number of people examined by two mature participants aged 60 years or older was $14.3 \%$. The mean and standard deviation of a sufficiently large age is 40.57 and 13.32 years, respectively. Among the many participants, 7 were single, 7 were married, and appeared independently in half and half of all participants.

\section{B. Fagerstrom Test for Nicotine Dependence}

Twelve participants scored eight in FTND considered $85.7 \%$, while two participants scored nine as $14.3 \%$. The mean and standard deviation were 8.14 and 0.35 .

\section{Lipopolysaccharide level}

The consequences of lipopolysaccharide level in the plasma appeared in the scope of 10 to $19 \mathrm{pg} / \mathrm{mL}$ as about $42.9 \%$, while $35.7 \%$ and $14.3 \%$ were considered in the scope of 20 to $29 \mathrm{pg} / \mathrm{mL} 30$ to $39 \mathrm{pg} / \mathrm{mL}$ independently. Just one participant came about 40-and-above lipopolysaccharide level checked out the proportion of $7.1 \%$ of the extensive number of individuals. The mean lipopolysaccharide level was $25.48 \mathrm{pg} / \mathrm{mL}$ with a standard deviation of $12.36 \mathrm{pg} / \mathrm{mL}$.

\section{Fagerstrom Nicotine Dependence Test and Lipopolysaccharide Level Correlation}

The Pearson correlation coefficient $(R)$ is a statistical measure of the strength of a linear relationship between two variables, with $\mathrm{R}=1$ denoting a complete positive correlation and $\mathrm{R}=-1$ denoting a complete negative correlation. The formula for Pearson's correlation coefficient $\mathrm{R}$ is:

$$
R=\frac{\sum(x-\bar{x})(y-\bar{y})}{\sqrt{\sum(x-\bar{x})^{2}} \sqrt{\sum(y-\bar{y})^{2}}}
$$

where;

$x$ is Fagerstrom Test for Nicotine Dependence

$y$ is lipopolysaccharide level

$\bar{x}$ is mean of Fagerstrom Test for Nicotine Dependence therefore;

$\bar{y}$ is mean of lipopolysaccharide level

The solution was appeared in Table III.

TABLE III

SOLUTION FOR PEARSON CORRELATION COEFFICIENT (R)

\begin{tabular}{ccccccc}
\hline$x$ & $y$ & $x-\bar{x}$ & $y-\bar{y}$ & $(x-\bar{x})(y-\bar{y})$ & $(x-\bar{x})^{2}$ & $(y-\bar{y})^{2}$ \\
\hline 8 & 16.008 & -0.143 & -9.470 & 1.353 & 0.020 & 89.680 \\
9 & 60.499 & 0.857 & 35.021 & 30.018 & 0.735 & 1226.48 \\
8 & 18.782 & -0.143 & -6.696 & 0.957 & 0.020 & 44.835 \\
8 & 26.337 & -0.143 & 0.859 & -0.123 & 0.020 & 0.738 \\
8 & 26.885 & -0.143 & 1.407 & -0.201 & 0.020 & 1.980 \\
8 & 27.849 & -0.143 & 2.371 & -0.339 & 0.020 & 5.622 \\
8 & 10.747 & -0.143 & -14.731 & 2.104 & 0.020 & 217.000 \\
8 & 35.343 & -0.143 & 9.865 & -1.409 & 0.020 & 97.320 \\
8 & 36.842 & -0.143 & 11.364 & -1.623 & 0.020 & 129.142 \\
9 & 17.325 & 0.857 & -8.153 & -6.988 & 0.735 & 66.470 \\
8 & 11.391 & -0.143 & -14.087 & 2.012 & 0.020 & 198.442 \\
8 & 27.16 & -0.143 & 1.682 & -0.240 & 0.020 & 2.829 \\
8 & 18.251 & -0.143 & -7.227 & 1.032 & 0.020 & 52.228 \\
8 & 23.272 & -0.143 & -2.206 & 0.315 & 0.020 & 4.866 \\
\hline \multicolumn{7}{r}{} \\
\hline
\end{tabular}


The value of $\mathrm{R}$ in Pearson relationship is 0.4438 . Albeit actually a positive correlation, the correlation between FTND and lipopolysaccharide level is weak. In addition, the estimation of $\mathrm{R}^{2}$, the coefficient of determination, is 0.197 . Pvalue is 0.1119 . Subsequently, there is no correlation between FTND and lipopolysaccharide level.

Human genetic testing predominates in the authoritative distinction of several genetic variants related to the risk of nicotine dependence and the severity of smoking. In order to extend these advances and help reduce the prevalence of smoking and the resulting damage to health, the following headings will distinguish between the genetic indicators of effective smoking cessation and the applicability of drugs to quit smoking in pharmacogenomics. More comprehensively, other biomarkers that can be evaluated from biological samples also ensure that they contribute to precision medicine and personalized treatment, including pharmacology and behavior [12].

$$
\begin{aligned}
& R=\frac{26.868}{\sqrt{(1.714)} \sqrt{(2137.628)}} \\
& R=0.4438
\end{aligned}
$$

Understanding smoking behavior requires phenotypic analysis and genotyping considerations. CHRNA5 / CHRNA3 mutations can regulate the receptor's response to nicotine, interfering with the behavior and dangers of smoking. Although the evidence clearly shows that the CHRNA5 rs16969968 variation is linked to the severity of smoking and tobacco use issues, smoking behavior is intricate and solves many mixed problems of genetic hazards. The CHRNA5 gene, which is found on chromosome 15 has the strongest genetic link to tobacco smoking, and many changes in this region clearly increase the risk of excessive smoking. The rs880395 mutation separates the second unmistakable affiliation. Utilitarian research highlights another organ system: the mRNA expression of the 5 nicotinic acetylcholine receptor subunits has undergone some overlapping changes.

Additionally, the low rate of recurrence and the rarity of mutations induced by other amino acid alterations in the nicotinic acetylcholine receptor subunit protein 5 are strongly associated with the differential risk of tobacco use disorders. Numerous reviews have emphasized the importance of the 5nicotine acetylcholine receptor subunit protein in the multiple dangers associated with excessive smoking, demonstrating the diverse utility of the quality expressed by the protein [13]. In a Brazilian population trial of 449 subjects, the relationship between CHRNA5 rs16969968 and CHRNA3 rs578776 and smoking behavior was studied. They found that with an OR of 3.09 (95 percent CI 1.09-8.76, $p=0.033$ ), women with the CHRNA5 rs16969968 AA genotype variant had a significantly greater risk of smoking. With an OR of 0.41 (95 percent CI: $0.19-0.88 ; p=0.022$ ), in the general population and women, the CHRNA3 rs578776 TT genotype has been shown to be safe for smoking and subsequent smoking. Taken together, in the Brazilian population test, the variants CHRNA5 rs16969968 and CHRNA3 rs578776 are linked to a higher risk of smoking and defense consequences. The sexual orientation and potential homozygosity of polymorphic variation greatly influence the results [14]. One previous study looked at four SNPs in the CHRNA5/A3/B4 acetylcholine receptor gene that had recently been linked to tobacco addiction. They were put to the test in a large number of untreated French young students (average age 20) and discovered compelling evidence (Long-term correction for multiple comparisons). The presence of tobacco dependency in young people can be detected using the numerous genetic variants in the studied genomes (rs637137, rs3813567, and rs16969968 dependent "AGG" haplotypes). The findings compete for the possibility of exploiting the CHRNA5/A3/B4 cholinergic receptor gene cluster's unique genetic markers in young people, so that it may more clearly help those who need help most (such as risk allele carriers), and produce More advantageous mediation on young subjects, or the process of raising the issue when smoking issues pass [15].

CHRNA5 quality encodes synaptic receptor subunits associated with various cycles, including cholinergic autonomic nerve activity and inflammation. In biological models of myocardial ischemia or reperfusion, excitation of the vagus nerve leads to a reduction in infarct size, the number of penetrating macrophages and polymorphonuclear leukocytes are reduced when the vagus nerve is stimulated, and a decrease in the number of penetrating macrophages and polymorphonuclear leukocytes, as well as a decrease in circulating cytokines, all of which are unrelated to cardiac frequency. The nicotine acetylcholine receptors in the vagus nerve reduce systemic inflammation (nAChRs).

$\mathrm{nAChR}$ is a ligand-activated heteropentameric particle that exists in neurons and non-neuronal cells, triggered by nicotine and acetylcholine. It is worth noting that the two primary subunits with strong mRNA and protein linkages in cardiac tissue are alpha5 $\mathrm{nAChR}$ and alpha $7 \mathrm{nAChR}$. The majority of $\alpha 7$ receptors are homopentamers, which are the key controllers of the anti-inflammatory pathway of vagus nerve intervention. When combined with other $\mathrm{AChR}$ subunits, the alpha5 receptor forms heteropentamers (including alpha7), and obstacles or hostility in the alpha5 nAChR pathway seem to upregulate the alpha7 nAChR pathway. Variants of the CHRNA5 gene (encoding the quality of nAChR alfa5) have been linked to tobacco use and the risk of chronic diseases such as lung cancer, COPD, diabetes, and atherosclerotic peripheral vascular disease (PVD). Inflammatory diseases [16]. GWAS recently discovered 45 vulnerability sites related to lung cancer. Single nucleotide polymorphisms (SNPs) in CHRNA3, CHRNA5, TERT, and human leukocyte antigen (HLA) regions have shown reliable and robust results in various examinations. Tumors are said to be immune-resistant and immune-suppressed, as well as resistant to cancer-related inflammation.

Early detection and individualized treatment require a deeper understanding of the link between lung cancer and this form of inflammation [17]. One of the previous studies investigated the mRNA expression of the interleukins IL-1, IL-6, IL-17, miR-9, and miR-122 as potential useful indicators for non-small cell lung cancer (NSCLC). It was observed that the expression of selected interleukins in noncancerous tissues was significantly higher than that in tumor tissues, and patients with a history of 40 pack-years (PY) (2,197, IQR: $0.821-4.415)$ and who were over 40 years old (0.461, IQR: $0.372-0.741 ; p=0.037$ ) had significantly greater levels of IL-6 in their tumor tissues. The up-regulation of IL1 and IL- 6 in tumors and surrounding tissues suggests that firing cycles have a role in NSCLC, and smoking can affect 
inflammation during tumorigenesis, which is manifested by an increase in IL-6 in patients' tumor tests [18].

Many studies have shown a link between smoking and inflammatory markers. During the inspection led by Feng et al., 984 current Chinese smokers from the ongoing infection review networks in Guangzhou and Zhuhai gathered about sociodemography, smoking, persistent conditions, and other health-related factors. C-reactive protein (CRP), interleukin (IL)-6, IL-1b, monocyte chemoattractant protein-1 (MCP-1), tumor necrosis factor (TNF-a), and vascular cell adhesion are all inflammation markers. VCAM-1 was estimated by flow cytometry. The recurrence rate was assessed to determine the function of inflammation in the smoking-hypertension connection. The association between smoking and hypertension was statistically significant $(p<0.05)$. After controlling for expected confounding factors, daily smoking is associated with elevated CRP and VCAM-1 levels and reduced TNF- $\alpha$ levels among the 6 estimated inflammatory markers. The levels are more significant in current smokers with hypertension. MCP -1 and CRP concentrations are higher than those of smokers with normal blood pressure.

Additionally, CRP disrupted the relationship between smoking and hypertension, accounting for 58.59 percent of smoking's estimated causal effect on hypertension [18], [19]. Furthermore, some previous studies focus on the heavy smokers in Bayi. Annual smoking, fasting blood glucose, alkaline phosphatase, and CRP levels were all found to have a favorable relationship. Waist circumference, body mass index (BMI), body fat, and trunk mass, as measured by DEXA and BIA, are all directly connected to packyears. In the leg press training estimated by $\mathrm{p} 1 \mathrm{RM}$, there is a negative correlation between smoking time per pack-year and muscle strength. A pack of years of smoking and CRP levels (inflammatory markers) maintain a favorable link after changes in age, gender, and BMI [18], [19], [20].

Nevertheless, there has been no research on the relationship between smoking and incendiary marker: the main target of lipopolysaccharide is the toll-like receptor-4, a crucial reaction in the inflammatory process. It is essential to recognize the association between smoking and inflammation. For this recent study, we focused on lipopolysaccharide due to there are numerous methods of novel treatment to balance lipopolysaccharide at the optimal level. If there were some associations, it might be one decision in the bioinformatics treatment of nicotine dependence as Coverstone et al. mentioned that CHRNA5 encodes a neurotransmitter receptor subunit related to different cycles, including cholinergic autonomic nerve movement and inflammation. Furthermore, this CHRNA5 realized loci are additionally genome-wide basic loci perceived for nicotine dependence. While there is no really effective therapy for nicotine addiction, a few treatments have been attempted, all of which are based on the concept that addressing the utilitarian resilience to nicotine with medications that target the receptors may minimize withdrawal and cravings, hence assisting in pharmacotherapeutic and holistic treatment approaches [19], [20], [21]. However, this study detailed a positive correlation between FTND and lipopolysaccharide level in the weak as a result of no correlation.

\section{CONCLUSION}

The final results revealed a positive association between the Fagerstrom Test for Nicotine Dependence and lipopolysaccharide in Thai smokers. Because there was no correlation between the Fagerstrom Test for Nicotine Dependence scores and lipopolysaccharide, the findings could impact scholarly activity in the field. However, it might associate with another inflammatory marker other than lipopolysaccharide. Further studies are recommended to investigate other bioinformatics inflammatory markers. Although this primary finding represents a general aspect of information, it may not affect all of the relations between smoking and inflammatory status.

\section{ACKNOWLEDGMENT}

We are grateful to everyone that took part in this study. We thank the entirety of the members associated with this research as primary information suppliers and might want to recognize the National Research Council of Thailand (Grant No. 126/2561); Tobacco Authorities of Thailand (Grant No. 4/2560). Authors thankfully recognize the Innovation Center for Holistic Health, Nutraceuticals and Cosmeceuticals, Faculty of Pharmacy, Chiang Mai University, Thailand, and Brain Science and Engineering Innovation Research Group, Mae Fah Luang University for the necessary arrangement and support. In contributing to this study, Parama Pratummas conceived and carried out the study; conducted the research; statistically analyzed and interpreted the data; carried out related studies search; prepared a drafted manuscript preparation; obtained funding. Phakkharawat Sittiprapaporn originated the concept; conceived of the study; carried out the research; and supervised the research; interpreted the data; obtained funding; critical revision of the manuscript. Chaiyavat Chaiyasut supervised the study. Sasithorn Sirilun supervised the study. Thamthiwat Nararatwanchai investigated the study. Phakkharawat Sittiprapaporn is the corresponding author.

\section{REFERENCES}

[1] J. Gauthier, A.T. Vincent, S.J. Charette, and N. Derome, "A brief history of bioinformatics," Brief Bioinform., vol. 20(6), pp. 1981-1996, 2019. doi: 10.1093/bib/bby063.

[2] R.K. Tiwari, V. Sharma, R.K. Pandey, and S.S. Shukla, "Nicotine Addiction: Neurobiology and Mechanism," J Pharmacopuncture., vol. 23(1), pp. 1-7, 2020. https://doi.org/10.3831/KPI.2020.23.001.

[3] K. Xu, B. Li, K.A. McGinnis, R. Vickers-Smith, C. Dao, N. Sun, R.L. Kember, H. Zhou, W.C. Becker, J. Gelernter, H.R. Kranzler, H. Zhao, A.C. Justice, and VA Million Veteran Program, "Genome-wide association study of smoking trajectory and meta-analysis of smoking status in 842,000 individuals," Nat Commun., vol. 11(1), 5302, 2020. https://doi.org/10.1038/s41467-020-18489-3.

[4] L.J. Bierut, and R.F. Tyndale, "Preparing the Way: Exploiting Genomic Medicine to Stop Smoking," Trends Mol Med., vol. 24(2), pp. 187-196, 2018. https://doi.org/10.1016/j.molmed.2017.12.001.

[5] J.I. de Granda-Orive, J.F. Pascual-Lledó, S. Asensio-Sánchez, S. Solano-Reina, M. da García-Rue, M.Á. Martínez-Muñiz, L. LázaroAsegurado, D. Bujulbasich, R. Pendino, S. Luhning, I. CienfuegosAgustínI, and C.A. Jiménez-Ruiz, "Fagerström Test and Heaviness Smoking Index. Are they Interchangeable as a Dependence Test for Nicotine?," Subst Use Misuse., vol. 55(2), pp. 200-208, 2020. https://doi.org/10.1080/10826084.2019.1660680.

[6] B. C. Quach, M. J. Bray, N. C. Gaddis, M. Liu, T. Palviainen, C. C. Minica, S. Zellers, R. Sherva, F. Aliev, M. Nothnagel, K. A. Young, J. A. Marks, H. Young, M. U. Carnes, Y. Guo, A. Waldrop, N. Y. A. Sey, M. T. Landi, D. W. McNeil, D. Drichel, L. A. Farrer, C. A. Markunas, 
J. M. Vink, J.-J. Hottenga, W. G. Iacono, H. R. Kranzler, N. L. Saccone, M. C. Neale, P. Madden, M. Rietschel, M. L. Marazita, M. McGue, H. Won, G. Winterer, R. Grucza, D. M. Dick, J. Gelernter, N. E. Caporaso, T. B. Baker, D. I. Boomsma, J. Kaprio, J. E. Hokanson, S. Vrieze, L. J. Bierut, E. O. Johnson, and D. B. Hancock, "Expanding the genetic architecture of nicotine dependence and its shared genetics with multiple traits," Nat Commun., vol. 11,5562, 2020. https://doi.org/10.1038/s41467-020-19265-z

[7] S. Papoutsopoulou, J. Satsangi, B.J. Campbell, and C.S. Probert, "Review article: impact of cigarette smoking on intestinal inflammation - direct and indirect mechanisms," Aliment Pharmacol Ther., vol. $51, \quad$ pp. $1268-1285$, 2020. https://doi.org/10.1111/apt.15774

[8] L. Mazgaeen, and P. Gurung, "Recent advances in lipopolysaccharide recognition systems," Int. J. Mol. Sci., vol. 21(2), 379, 2020. https://doi.org/10.3390/ijms21020379

[9] B. Boonen, Y.A. Alpizar, A. Sanchez, A. López-Requena, T. Voets, and K. Talavera, "Differential effects of lipopolysaccharide on mouse sensory TRP channels," Cell Calcium, vol. 73, pp. 72-81, 2018 https://doi.org/10.1016/j.ceca.2018.04.004.

[10] Y.A. Alpizar, B. Boonen, A. Sanchez, C. Jung, A. López-Requena, R. Naert, B. Steelant, K. Luyts, C. Plata, V.D. Vooght, J.A.J. Vanoirbeek, V.M. Meseguer, T. Voets, J.L. Alvarez, P.W. Hellings, P.H.M. Hoet, B. Nemery, M.A. Valverde, and K. Talavera, "TRPV4 activation triggers protective responses to bacterial lipopolysaccharides in airway epithelial cells," Nat Commun., vol. 8, 1059, 2017. https://doi.org/10.1038/s41467-017-01201-3

[11] L. Salhi, L. Seidel, A. Albert, and F. Lambert, "Fagerström test for nicotine dependence as an indicator in tobacco-related studies in periodontology," J Periodontol., vol. 92(2), pp. 298-305, 2021. https://doi.org/10.1002/JPER.20-0019.

[12] N.L. Saccone, J.W. Baurley, A.W. Bergen, S.P. David, H.R. Elliott, M.G. Foreman, J. Kaprio, T.M. Piasecki, C.L. Relton, L. Zawertailo, L.J. Bierut, R.F. Tyndale, L.S. Chen, and Genetics and Treatment Networks of the Society for Research on Nicotine and Tobacco (SRNT), "The Value of Biosamples in Smoking Cessation Trials: A Review of Genetic, Metabolomic, and Epigenetic Findings," Nicotine \& tobacco research : official journal of the Society for Research on Nicotine and Tobacco, vol. 20(4), pp. 403-413, 2018. https://doi.org/10.1093/ntr/ntx096

[13] L.J. Bierut, "Langley Award for Basic Research on Nicotine and Tobacco: Bringing Precision Medicine to Smoking Cessation," Nicotine Tob Res., vol. 22(2), pp. 147-151, 2020. https://doi.org/10.1093/ntr/ntz036.

[14] C.L. Mota, S. Mitri, C. Barata-Silva, and J.C. Moreira, "CHRNA5/CHRNA3 polymorphisms and tobacco smoking risk in a
Brazilian population sample," GSC Biol. Pharm. Sci., vol. 12(2), pp. 143-152, 2020. https://doi.org/10.30574/gscbps.2020.12.2.0253

[15] Y.L. Strat, N. Ramoz, and P. Gorwood, "Evidence for the association of the nicotinic acetylcholine receptor CHRNA5/A3/B4 gene cluster and nicotine dependence in a young population of students," French $J$. Psychiatry, vol. 6898(100), pp. S1-S182, 2020 http://dx.doi.org/10.1016/j.fjpsy.2020.09.001

[16] E.D. Coverstone, R.G. Bach, L. Chen, L.J. Bierut, A.Y. Li, P.A Lenzini, H.C. O'Neill, J.A. Spertus, C.C. Sucharov, J.A. Stitzel, J.D Schilling, and S. Cresci, "A novel genetic marker of decreased inflammation and improved survival after acute myocardial infarction,”. Basic Res Cardiol., vol. 113(5), 38, 2018. https://doi.org/10.1007/s00395-018-0697-7.

[17] J. Dai, M. Huang, C.I. Amos, R.J. Hung, A. Tardon, A. Andrew, C. Chen, D.C. Christiani, D. Albanes, G. Rennert, J. Fan, G. Goodman, G. Liu, J.K. Field, K. Grankvist, L.A. Kiemeney, L. Le Marchand, M.B. Schabath, M. Johansson, M.C. Aldrich, M. Johansson, N. Caporaso, P. Lazarus, S. Lam, S.E. Bojesen, S. Arnold, M.T. Landi, A. Risch, H.E. Wichmann, H. Bickeboller, P. Brennan, S. Shete, O. Melander, H. Brunnstrom, S. Zienolddiny, P. Woll, V. Stevens, Z. Hu, and H. Shen, "Genome-wide association study of INDELs identified four novel susceptibility loci associated with lung cancer risk," Int $J$ Cancer., vol. 146(10), pp. 2855-2864, 2020. doi: 10.1002/ijc.32698.

[18] A. Dutkowska, B. Szmyd, M. Kaszkowiak, and D. Daria DomańskaSenderowska, D. Pastuszak-Lewandoska, E. Brzeziańska-Lasota, J. Kordiak, and A. Antczak, "Expression of inflammatory interleukins and selected miRNAs in non-small cell lung cancer," Sci Rep., vol. 11, 5092, 2021. https://doi.org/10.1038/s41598-021-84408-1

[19] R.L. Papke, D.H. Brunzell, and M. De Biasi, "Cholinergic Receptors and Addiction. Curr Top Behav Neurosci., vol. 45, pp. 123-151, 2020 https://doi.org/10.1007/7854 2020 139 .

[20] A. Jackson, D. Bagdas, P.P. Muldoon, A.H. Lichtman, F.I. Carroll, M. Greenwald, M.F. Miles, and M.I. Damaj, "In vivo interactions between $\alpha 7$ nicotinic acetylcholine receptor and nuclear peroxisome proliferator-activated receptor- $\alpha$ : Implication for nicotine dependence. Neuropharmacology, vol. 15(118), pp. 38-45, 2017. https://doi.org/10.1016/j.neuropharm.2017.03.005.

[21] R.M. Schuster, G.N. Pachas, L. Stoeckel, C. Cather, M. Nadal, D. Mischoulon, D.A. Schoenfeld, H. Zhang, C. Ulysse, E.B. Dodds, S. Sobolewski, V. Hudziak, A. Hanly, M. Fava, and A.E. Evins, "Phase IIb Trial of an $\alpha 7$ Nicotinic Receptor Partial Agonist With and Without Nicotine Patch for Withdrawal-Associated Cognitive Deficits and Tobacco Abstinence," J Clin Psychopharmacol., vol. 38(4), pp. 307316, 2018. https://doi.org/10.1097/JCP.0000000000000919. 